$12-26-2018$

\title{
Risk, standard deviation, and expected value: when should an individual start social security?
}

\author{
T. G. Eschenbach
}

Neal Lewis

Fairfield University, nlewis@fairfield.edu

Follow this and additional works at: https://digitalcommons.fairfield.edu/business-facultypubs Copyright 2018 Taylor \& Francis

The author post-print has been archived here with permission from the copyright holder.

\section{Peer Reviewed}

\section{Repository Citation}

Eschenbach, T. G. and Lewis, Neal, "Risk, standard deviation, and expected value: when should an individual start social security?" (2018). Business Faculty Publications. 229.

https://digitalcommons.fairfield.edu/business-facultypubs/229

\section{Published Citation}

Eschenbach, Ted G., and Neal A. Lewis. "Risk, standard deviation, and expected value: when should an individual start social security?." The Engineering Economist (2018): 1-16. https://doi.org/10.1080/0013791X.2018.1532543.

This item has been accepted for inclusion in DigitalCommons@Fairfield by an authorized administrator of DigitalCommons@Fairfield. It is brought to you by DigitalCommons@Fairfield with permission from the rightsholder(s) and is protected by copyright and/or related rights. You are free to use this item in any way that is permitted by the copyright and related rights legislation that applies to your use. For other uses, you need to obtain permission from the rights-holder(s) directly, unless additional rights are indicated by a Creative Commons license in the record and/or on the work itself. For more information, please contact digitalcommons@fairfield.edu. 


\section{Risk, Standard Deviation, and Expected Value: When Should an Individual Start Social Security?}

Ted G. Eschenbach

University of Alaska Anchorage
Neal A. Lewis

Fairfield University

\section{Abstract}

In choosing when to start collecting social security, the differences in expected NPVs are small — but the corresponding standard deviations are not. Starting earlier is less risky. The case analyzed is single individuals in the U.S. system, but the methodology can be applied to couples and to the systems of other nations. Considering risk and return together places social security in the same risk/return framework as other capital investments. Behavioral, situational, and qualitative factors that often dominate decisions on when to start are linked with quantitative approaches to longevity risk and mortality risk.

\section{Defining the problem}

Social security is a U.S. government program providing retirement and other benefits to eligible people. The choice of when to begin retirement benefits is up to the individual, and much has been written about when to begin benefits. This work extends consideration of risk in the decision framework.

The results presented here contribute to a specifically defined problem — when should a single, eligible individual with the required 40 U.S. Social Security "credits or quarters" start their retirement benefit. While benefits may begin in any given month, the exemplar choices are collecting reduced benefits as early as age 62, receiving a primary insurance amount (PIA) by waiting until full retirement age (the FRA is currently 66 with gradual increases beginning with those who turn 66 in 2021), or delaying up to age 70 for enhanced payments. No article can do more than contribute to an understanding of this problem and its solutions. There is too much 
variety in individual situations and motivations, there are too many behavioral factors, there are both qualitative and quantitative aspects, and different types of risk are best measured differently. Examples are described as one of the limitations of this work.

This work specifically addresses the problem of what can be learned by considering both expected values and standard deviations of incremental NPVs and IRRs. Previous work included expected values of retirement benefits based on mortality data, but not the corresponding standard deviations presented here. The large differences in standard deviations that are demonstrated are more important than smaller differences in expected values. This work also specifically addresses the problem of how to value social security benefits relative to other retirement funding sources — which are normally characterized by their expected value and standard deviation of historical or predicted annual returns. In contrast, the risks linked to social security are often described in qualitative terms only. Analyzing incremental IRRs provides two key results: (1) delaying benefits has negative expected IRRs and (2) delay has relatively large standard deviations. The results of this work were stable when analyzed for the mortality data of several demographic sub-groups that live longer or die sooner than average.

At a broad definition of the problem, this work's methodology can be applied to any nation's pension or firm's retirement system where the annual benefit received depends on the age at which the recipient chooses to start benefits. This application only depends on the individual having a choice and the analyst having the relevant mortality distribution(s) and program details. Applying the methodology does not depend on how a national pension system determines who is qualified nor on how benefit levels are calculated. Other national programs are summarized in Social Security Administration (2016, 2017a, 2017b, and 2018a), which are the most recent of the bi-annual updates for each of 4 world regions. While the work presented 
here focuses on single individuals within the U.S. social security system, the methodology could be applied to those who are or were in a couple relationship where either partner is or will be eligible to receive benefits such as spousal or survivor's benefits in the U.S. system or in the systems of other countries.

\section{Previous work}

\section{System design and claimant behavior}

The Social Security Administration's website (ssa.gov) and publications are the most authoritative source, but some of the clearest descriptions are found in material developed for potential claimants. The first step in computing benefits is the individual's average indexed monthly earnings (AIME). This is based on the claimant's highest 35 years of earnings (subject to social security withholding), adjusted for inflation and for the claimant's social security (SS) income relative to average SS income in each year. In 2018 each $\$ 1320$ of income subject to social security taxes earns 1 credit up to a maximum of 4 credits per year. If there are only the required 40 credits and they are concentrated in only 10 years, then 25 years of $\$ 0$ are included in calculating AIME. The full retirement age monthly benefit (maximum $\$ 2,927$ in 2018) known as the primary insurance amount (PIA) is computed from the maximum AIME of $\$ 9,936$ (for 2018). Equation 1 and Figure 1 show how PIA is calculated, using 'bend points' ( $\$ 895$ and $\$ 5,397)$ and multipliers $(0.9,0.32$, and 0.15$)$. If benefits start at age 62 , benefits are reduced to $75 \%$ of the PIA; if benefits are delayed until age 70 , benefits are enhanced to $132 \%$ of the PIA. Each year the benefit received is adjusted for inflation and for any new income that increases the AIME.

$$
P I A=0.9(895)+0.32(5,397-895)+0.15(9,936-5,397)=\$ 2,927 \text { for } \mathrm{AIME}=\$ 9,936
$$




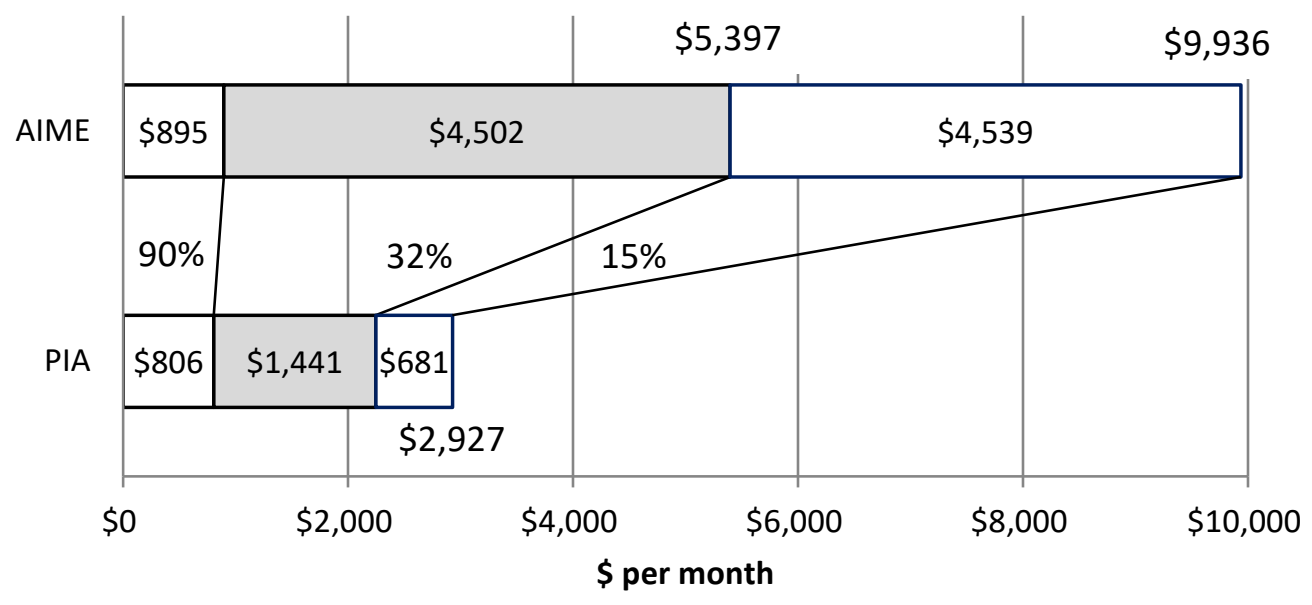

Figure 1. AIME to monthly PIA

A majority of people start social security benefits at their earliest opportunity (Coile et al. 2002; Knoll 2011; Muldoon and Kopcke 2008). For those 65 or older nearly $90 \%$ receive SS benefits (Social Security Administration 2018b). With 10,000 people now turning 65 every day (Cohn and Taylor 2010), this is a decision faced by many.

Claiming benefits before full retirement age is less attractive for those with income subject to social security taxes. In the years before FRA, benefits are reduced by $\$ 1$ for every $\$ 2$ earned over $\$ 17,040$ per year (for 2018). In the year a person reaches FRA, benefits are reduced by $\$ 1$ for every $\$ 3$ earned over $\$ 45,360$ (for 2018) in the months before FRA. The benefit reductions are delayed benefits and not lost benefits (though spousal benefits may be lost). If benefits start at or after FRA, then there are no income limits.

As assumed here, previous work assumed that analysis of starting before FRA is warranted only if these income limits do not apply. Results are for a selected set of ages at death (Munnell and Soto 2005; Novack 2011) or for average or median life expectancies (Meyer and Reichenstein 2010; Shoven and Slavov 2012; Eschenbach, Lewis, and Zhang 2012). The social 
security system was designed to be "benefit neutral" for single individuals. For these individuals with an average age at death the NPV of benefits is roughly the same no matter when benefits start (Cook, Jennings, and Reichenstein 2002; Jivan 2004; Sass, Sun, and Webb 2007).

\section{Limitations of previous work and this work}

Income taxes are not considered by this work as in most previous work; exceptions include Boskin et al. (1987) and Kotlikoff (1996). The challenges of considering income taxes include:

(1) the proportion of social security benefits taxed is $0 \%, 50 \%$, or $85 \%$ depending on income, (2) the marginal tax rate depends on total taxable income, (3) different states tax $0 \%$ to $100 \%$ of the benefits, and (4) individuals pay taxes at different rates over their time of receiving benefits. There are situations where federal income taxes provide an incentive to delay or start benefits. If income and tax rates are high now, but will drop significantly after the individual retires, then delay looks better. If income is low now and required minimum distributions will trigger higher tax rates, then starting early looks better.

This work and much of the previous work considers only single individuals and does not include those who are or were in a couple relationship where either partner is or will be eligible to receive spousal or survivor's benefits. These benefits are in addition to the retirement benefit of individuals (Lewis and Eschenbach 2013). Applying the methodology used here to couples would require considering the ages and PIAs of both partners and more complex strategies described in Reichenstein and Meyer (2017), which are beyond the scope of this work.

Like previous work on recommended strategies, this work does not address provisions that may affect eligibility and the level of benefits. Examples of issues that are not addressed include the governmental pension offset (GPO), the windfall elimination provision (WEP), and consideration of military service. 
Previous work has described mortality risk as the risk of collecting less (or nothing) if you die earlier than expected. Friedman and Phillips (2010) found that there are negative yields for many years from a one-year delay of benefits and that risk-averse people should start social security benefits as soon as income penalties end. The work presented here focuses on one measure of risk - the standard deviation of possible NPVs and IRRs. There are other measures, such as the semivariance, which only considers deviations below the average. While semivariance is not addressed further, it would emphasize that a delay in starting benefits would risk collecting little or nothing in the event of an early death. Opportunity loss (another measure of risk) has been used to calculate break-even ages at death (Alleva 2015).

It has been argued in the popular press that starting benefits earlier reduces the risk of receiving less due to program changes. However when the value of benefits has been lowered in the past, "grandfathering" of current recipients and long periods before implementation have been common. For example, raising the full retirement age from 65 to 67 was discussed for years, signed into law in 1983 (Dewitt, 2010), first raised to 65 years and 2 months in 2000, and the last currently scheduled change to 67 occurs in 2022 .

This and previous work cannot judge the relative importance of behavioral, qualitative, and quantitative factors that may contribute to or dominate the choice of when to start benefits. This work can and does address the lesser importance of the expected value as compared with the standard deviation when considered together as quantitative measures for single individuals choosing a starting age.

This work recognizes that individual decisions and more general recommendations require a more wholistic view. The proper balance of factors in a particular decision depends on individual situations and motivations. How much does a person may want to leave for heirs? 
What is their risk attitude toward running out of money? How important are the expected value and standard deviation of the retirement benefit? While many decisions are made with incomplete knowledge and understanding, the authors assert that the following examples illustrate why many individuals start benefits at or before FRA. Claiming benefits earlier can (1) allow retirement and more time for desired activities; (2) support activities before health and vigor declines; (3) preserve money "in the bank" for events requiring a lump sum rather than a higher monthly benefit; (4) maximize benefits in the face of a terminal illness or life-shortening health problems; and (5) preserve current investments for bequests if the investments are not needed for later living expenses (Lockwood 2011). Ahn and Yoon (2011) describe an analogous tradeoff between labor, leisure, and investment. Claiming benefits later (1) is a form of required saving and (2) is a form of longevity insurance - which is addressed more fully in the next section.

From a more academic perspective, it is suggested that (1) regret of possible losses is often larger than the value of similarly sized gains (Bell 1982); and (2) collecting social security is an annuity and like most economic goods it is subject to decreasing marginal utility (Kauder 1953). Thus collecting incrementally more annuity insurance from delaying benefits will have a lower marginal value than the basic benefit.

Gustman and Steinmeier (2005) use heterogeneity in time preferences measured by discount rates to explain why individuals prefer to start benefits early. Other work that focuses on including risk in a variety of contexts includes Gradl, et al. (2009), Ho and Pike (1998), and Lohmann and Baksh (1993). 


\section{Longevity risk}

How does an individual support themselves if they live longer than expected? This longevity risk can be addressed with annuities that are priced for those that expect a disproportionately long life. Annuities are promoted as a hedge against longevity risk, but payouts average $81 \varnothing$ per dollar invested (Mitchell et al. 1999) in contrast with the positive returns expected from investments. Another approach is to delay social security benefits to maximize the monthly payment (Sun and Webb 2009; Meyer and Reichenstein 2010). Delaying social security is a "free" annuity, because the expected values for different starting dates change so little (Sun and Webb 2011). If longevity risk is the dominant concern, then benefits should not be started until age 70 . However, from early annuity work (Yaari 1965) it is usually assumed that the consumer has no bequest motive, and thus sees no value to wealth after death (Davidoff et al. 2005). In fact, most people do have a bequest motive; it is estimated that $75 \%$ of elderly single households want to leave a positive net worth estate for their heirs (Kopczuk and Lupton 2007).

Manakyan et al. (2014) addressed longevity risk by simulating outcomes of starting benefits late vs. early and investing in portfolios ranging from all bonds to all stocks at survival ages of 86,91 , and 96 . In most cases, claiming early and investing mainly in stocks was the best strategy. In contrast, Blanchett (2012) concluded starting benefits early and investing would earn 9.15\% less than delaying benefits for a hypothetical married couple.

The analysis of longevity risk is complicated by the fact that there are behavioral answers to, "How does an individual support themselves if they live longer than expected?" For example, some retirees believe that moving in with family as health and assets decline is not just expected, but valued. As another example, claiming benefits earlier may be possible because near and 
long-term behavior can be adjusted to match near and long-term income and expenditures. Travel or meals out can be adjusted as needed to be rare and cheap or common and expensive.

The work presented here does not suggest that longevity risk can be ignored. However, balancing longevity risk with other factors requires consideration of bequest motives and possible behavioral changes. The authors assert the fundamental importance of recognizing that retirement benefits, even when started early, do address longevity risk. Delaying benefits simply gains incremental reductions in longevity risk.

\section{Assumptions}

Assumptions described previously include: a single individual starting benefits of $0.75 \times \mathrm{PIA}$ at 62 , of $1 \times$ PIA at 66 , or of $1.32 \times$ PIA at 70 ; results are pre-tax; and a PIA that equals the monthly maximum of $\$ 2927$ (annual total $=\$ 35,124$ ). Results for intermediate ages can be interpolated (though minor maximums can occur), and all results stated in dollars can be scaled to match any lower PIA.

For ease of computation, we assume that the individual's $62^{\text {nd }}$ birthday is January $2^{\text {nd }}$ so that the person will receive a full first year's benefit (SSA, 2004). If a birthday of January $1^{\text {st }}$ is assumed, then the bend points (see Equation 1) for the previous year must be used. Matching assumptions of end-of-year cash flows and end-of-year deaths are made in order to match the annual mortality data. Note that assuming mid-year or monthly cash flows would increase the economic value of benefits by a factor of about $1+i / 2$ (where $i$ is the real interest rate), thus relative and incremental expected values will not change. Standard deviations will simply increase by the multiplicative factor, which is close to 1 so relative values will change little.

Conditional probabilities regarding age at death assume a person is alive at 62 , and are calculated using current mortality data (2014) from the National Vital Statistics System (Arias, 
2017). If similarly reliable monthly data were available or deaths were assumed to be mid-year, then the final year of benefits would be approximately halved. This does decrease the economic value of the benefit stream, so this is an assumption that is an opportunity for further research.

Because social security benefits do receive cost of living adjustments, all benefits are stated in constant value dollars. A real interest rate of 3\% is assumed for most computations, as that has been commonly used in the literature and by the Social Security Administration (Cook, Jennings, and Reichenstein 2002; Munnell and Soto 2005; Sass, Sun, and Webb 2008).

For descriptive purposes, the first results presented are for the net present value of benefits at starting ages of 62,66 , and 70 . This also supports a very important point. These results cannot be used to calculate the standard deviation of incremental benefits, as that would incorrectly assume independent, identically distributed random variables for age at death for each starting age. Instead, the correct assumption is to assume a single random variable for age at death and then calculate the incremental NPVs or IRRs. This is analogous to a paired difference model.

\section{Expected NPV and risk}

Equation 1 defines the annual benefit (APIA) that is received from the age at start $(s)$ until the age at death $(d)$. Equation 2 details the calculation of the benefit stream's NPV. Because of annual compounding, benefits are considered at the end of the year received, so benefits received during age 62 are identified as year 63 . Thus, age 62 is time 0 , and 63 is the end of period 1 . Table 1 shows example conditional probabilities for age at death given that a person is alive at 62, derived from the NVSS data (Arias, 2017). In particular, note that the probability of dying before collecting (shown in Table 2$)$ is $4.48 \%$ for starting benefits at age $66(=0.0103+0.0109$ $+0.0115+0.0121$ from Table 1). Similarly, the probability of dying before age 70 (assuming being alive at 62 ) is $10.12 \%$. 


$$
\begin{gathered}
A P I A_{s}=12 \times\{0.75,1,1.32\} \times P I A \quad \text { for } s=62,66,70 \\
N P V_{s, d}=\frac{1}{(1+i)^{s-62}} \sum_{t=s}^{d} \frac{A P I A_{s}}{(1+i)^{t-62}} \quad \text { for } d=[63,101]
\end{gathered}
$$

Table 1. Example conditional dying probabilities given alive at 62 derived from NVSS data for all individuals.

\begin{tabular}{cccc}
$\begin{array}{c}\text { Year } \\
\text { ending } \\
\text { at Age }\end{array}$ & P(die|62) & $\begin{array}{r}\text { Year } \\
\text { ending } \\
\text { at Age }\end{array}$ & P(die|62) \\
\hline 63 & 0.0103 & 94 & 0.0318 \\
64 & 0.0109 & 95 & 0.0284 \\
65 & 0.0115 & 96 & 0.0246 \\
66 & 0.0121 & 97 & 0.0208 \\
67 & 0.0128 & 98 & 0.0171 \\
68 & 0.0136 & 99 & 0.0136 \\
69 & 0.0145 & 100 & 0.0105 \\
70 & 0.0155 & $\geq 101$ & 0.0242
\end{tabular}

Figure 2 is the basis of the first major conclusion. For single individuals, differences in standard deviation are much larger and thus more important than the much smaller differences in expected value for different starting ages. Recall that the preferred direction on the return (or $y$ axis) is up and on the standard deviation (or $x$-axis) is to the left. Figure 2 shows that at a $3 \%$ real interest rate the expected values (measured on the $y$-axis) are virtually equivalent for each starting age, but the standard deviations are not. Only at $0 \%$ do we see the "normal" tradeoff between risk and return where expecting a higher return is paired with a higher risk. Again, small increases in NPV are paired with large increases in risk. At a $6 \%$ real interest rate, starting as early as possible is a dominant strategy considering these two measures with higher expected returns and lower risks. 


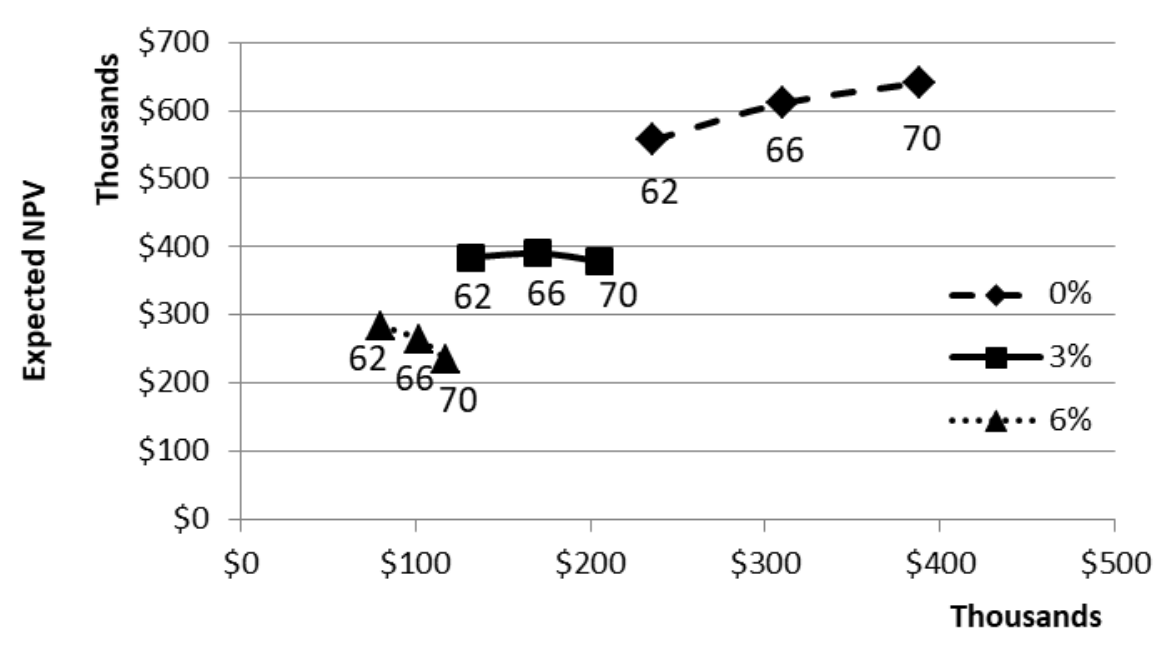

Standard deviation

Figure 2. NPV's risk and expected return for total population for starting ages of 62, 66, and 70 at real interest rates of $0 \%, 3 \%$, and $6 \%$.

Table 2 details the descriptive statistics for this data. If this were to be used to calculate the incremental difference between starting at 62 and 66, the expected value difference of $\$ 5821$ $(=390,531-384,710)$ would be correct. However, it would be wrong to calculate the standard deviation of the difference as $\$ 215,403=\sqrt{131,227^{2}+170,186^{2}}$ because the variables are not independent. The next section presents results for this work's assumption of a single conditional probability distribution for each class of individuals.

Table 2. Descriptive statistics for the NPV of benefits at $3 \%$ real interest.

\begin{tabular}{rccr} 
& Start 62 & Start 66 & Start 70 \\
\cline { 2 - 4 } Expected NPV & $\$ 384,710$ & $\$ 390,531$ & $\$ 379,019$ \\
Std. dev. & $\$ 131,227$ & $\$ 170,186$ & $\$ 205,574$ \\
$\mathrm{P}$ (die before start) & 0 & $4.48 \%$ & $10.12 \%$
\end{tabular}

\section{Incremental NPV}

Calculating incremental NPVs for each year of death is simply the difference between two applications of Equations 2 and 3-an earlier start at 62 or 66 and a later start at 66 or 70 . Unlike the mortality distributions which depend on gender, the NPV calculations do not. Thus, there is 
only one set of $\triangle \mathrm{NPV}$ s for each incremental comparison. The increment order is chosen to match the normal engineering economic incremental assumption that each increment is an investment. In this case, the investment is forgoing earlier year payments to qualify for larger payments in later years. The results in Table 3 are for the maximum PIA, but they can be scaled for any other PIA value.

Table 3. Incremental NPVs at $3 \%$ real interest.

\begin{tabular}{rrrrcc} 
Die at & $\Delta \mathrm{NPV}_{66-62}$ & \multicolumn{1}{c}{$\Delta \mathrm{NPV}_{70-66}$} & Die at & $\Delta \mathrm{NPV}_{66-62}$ & $\Delta \mathrm{NPV}_{70-66}$ \\
\hline 63 & $-\$ 24,361$ & $\$ 0$ & 94 & $\$ 46,172$ & $\$ 32,627$ \\
64 & $-\$ 48,013$ & $\$ 0$ & 95 & $\$ 49,326$ & $\$ 36,663$ \\
65 & $-\$ 70,976$ & $\$ 0$ & 96 & $\$ 52,387$ & $\$ 40,582$ \\
66 & $-\$ 93,269$ & $\$ 0$ & 97 & $\$ 55,360$ & $\$ 44,386$ \\
67 & $-\$ 86,055$ & $-\$ 28,859$ & 98 & $\$ 58,246$ & $\$ 48,080$ \\
68 & $-\$ 79,050$ & $-\$ 56,878$ & 99 & $\$ 61,048$ & $\$ 51,666$ \\
69 & $-\$ 72,249$ & $-\$ 84,081$ & 100 & $\$ 63,768$ & $\$ 55,148$ \\
70 & $-\$ 65,647$ & $-\$ 110,492$ & $\geq 101$ & $\$ 66,409$ & $\$ 58,528$
\end{tabular}

Table 4 summarizes the results for the total population and by gender by applying each category's conditional probabilities. Delaying from 66 to 70 results in a negative $\mathrm{E}(\Delta \mathrm{NPV})$ in all of these cases. Delaying from 62 to 66 results in either negative or significantly smaller $\mathrm{E}(\triangle \mathrm{NPV})$ than the corresponding standard deviations. Note that the standard deviations, while large compared to the expected values, are substantially smaller than the $\$ 215,403$ that was calculated for hypothetical independent probability distributions.

Table 4. Summary statistics for incremental NPV at 3\% real interest.

$$
\text { Total population Female Male }
$$

\begin{tabular}{ccccccc} 
& $66-62$ & $70-66$ & $66-62$ & $70-66$ & $66-62$ & $70-66$ \\
\cline { 2 - 7 } E $(\Delta \mathrm{NPV})$ & $\$ 5,821$ & $-\$ 11,512$ & $\$ 11,169$ & $-\$ 6,299$ & $-\$ 185$ & $-\$ 17,431$ \\
Std. dev. & $\$ 40,004$ & $\$ 42,533$ & $\$ 38,994$ & $\$ 42,176$ & $\$ 40,078$ & $\$ 41,951$ \\
Coef. Var. & 6.87 & -3.69 & 3.49 & -6.70 & -216.77 & -2.41
\end{tabular}


It is these results that specifically address the problem of what can be learned by considering both expected values and standard deviations of incremental NPVs. The larger differences in standard deviations that are demonstrated are more important than smaller differences in expected values. These results contribute to the solution of when a single individual should start social security.

\section{Incremental rate of return}

This section addresses the problem of how to value social security benefits relative to other retirement funding sources — which are normally characterized by the expected value and standard deviation of historical or predicted annual returns. Analyzing incremental IRRs provides two key results: (1) delaying benefits has negative expected IRRs and (2) delay has relatively large standard deviations. Delaying benefits results in both lower expected returns and higher standard deviations than for other retirement investments.

The higher risk of social security is particularly notable because the older an individual, the more conservative the recommended investment portfolio becomes. Bear markets (time periods where stock prices are decreasing) are part of the volatility of long-term investing; however, a bear market just before or during retirement can shrink portfolios below what is needed for a retiree's well-made plan. At the average age at death, delaying starting benefits is similar to living in a bear market during much of retirement.

Because incremental IRR analysis is based on cash flows, it is easiest to use the PIA multipliers of $75 \%, 100 \%$, and $132 \%$ for starting at 62,66 , and 70 respectively. Starting benefits at age $66(=$ time 0$)$ means forgoing the $75 \%$ benefit that could have been received at $63,64,65$, and 66. Instead, 25\% more is received from 67 until death. Similarly waiting until age 70 instead of starting at 66 means forgoing the $100 \%$ that could have been received at 67, 68, 69, and 70 . 
Instead $32 \%$ more is received from 71 until death.

Equations 4 and 5 are solved to find the incremental IRRs if death occurs after positive incremental benefits are started. If death occurs before the delayed benefits are started, then the $\triangle I R R$ cannot be calculated; however, this is conceptually a complete "loss of investment" or complete "loss of the opportunity to receive benefits" or a $-100 \%$ incremental IRR. Again, benefits are considered at the end of the year received, so benefits qualified for at a time 0 of age 62 are identified as year 63. Note that representative values shown in Table 5 do not depend on any mortality distribution.

$$
\begin{aligned}
& \Delta I R R_{66-62}=i \text { such that } 0=\sum_{t=63}^{66} \frac{-0.75}{(1+i)^{t-62}}+\sum_{t=67}^{d} \frac{1}{(1+i)^{t-67}} \text { for } d \geq 67 \\
& \Delta I R R_{70-66}=i \text { such that } 0=\sum_{t=66}^{70} \frac{-1}{(1+i)^{t-66}}+\sum_{t=71}^{d} \frac{0.32}{(1+i)^{t-70}} \text { for } d \geq 71
\end{aligned}
$$

Table 5. Incremental IRRs.

\begin{tabular}{rccccc} 
Die at & $\Delta \mathrm{IRR}_{66-62}$ & $\Delta \mathrm{IRR}_{70-66}$ & Die at & $\Delta \mathrm{IRR}_{66-62}$ & $\Delta \mathrm{IRR}_{70-66}$ \\
\hline 63 & $-100 \%$ & - & 94 & $6.2 \%$ & $5.2 \%$ \\
64 & $-100 \%$ & - & 95 & $6.3 \%$ & $5.4 \%$ \\
65 & $-100 \%$ & - & 96 & $6.4 \%$ & $5.6 \%$ \\
66 & $-100 \%$ & - & 97 & $6.5 \%$ & $5.7 \%$ \\
67 & $-74.9 \%$ & $-100 \%$ & 98 & $6.6 \%$ & $5.8 \%$ \\
68 & $-48.6 \%$ & $-100 \%$ & 99 & $6.6 \%$ & $6.0 \%$ \\
69 & $-33.6 \%$ & $-100 \%$ & 100 & $6.7 \%$ & $6.1 \%$ \\
70 & $-24.0 \%$ & $-100 \%$ & $\geq 101$ & $6.8 \%$ & $6.2 \%$
\end{tabular}

Figure 3 graphs the incremental IRR vs. age at death. This emphasizes that if an individual dies within 16 years of making the decision to delay (age 78 for delaying from 62 to 66, and 82.5 for delaying from 66 to 70) delay has a negative incremental IRR—often extremely negative. On 
the other hand, living into your 90's only earns positive incremental rates of return of about $5 \%$ to $7 \%$ (see also Friedman and Phillips 2010). A real interest rate of 3\% was used as the MARR for NPV calculations, and it can be used as a hurdle rate for the IRR. Delaying from age 62 to 66 achieves a 3\% IRR at age 81.0 (when the general population has a $40.0 \%$ probability of being deceased), and delaying from 66 to 70 achieves a 3\% IRR at age 85.8 (with a $59.3 \%$ probability of being deceased).

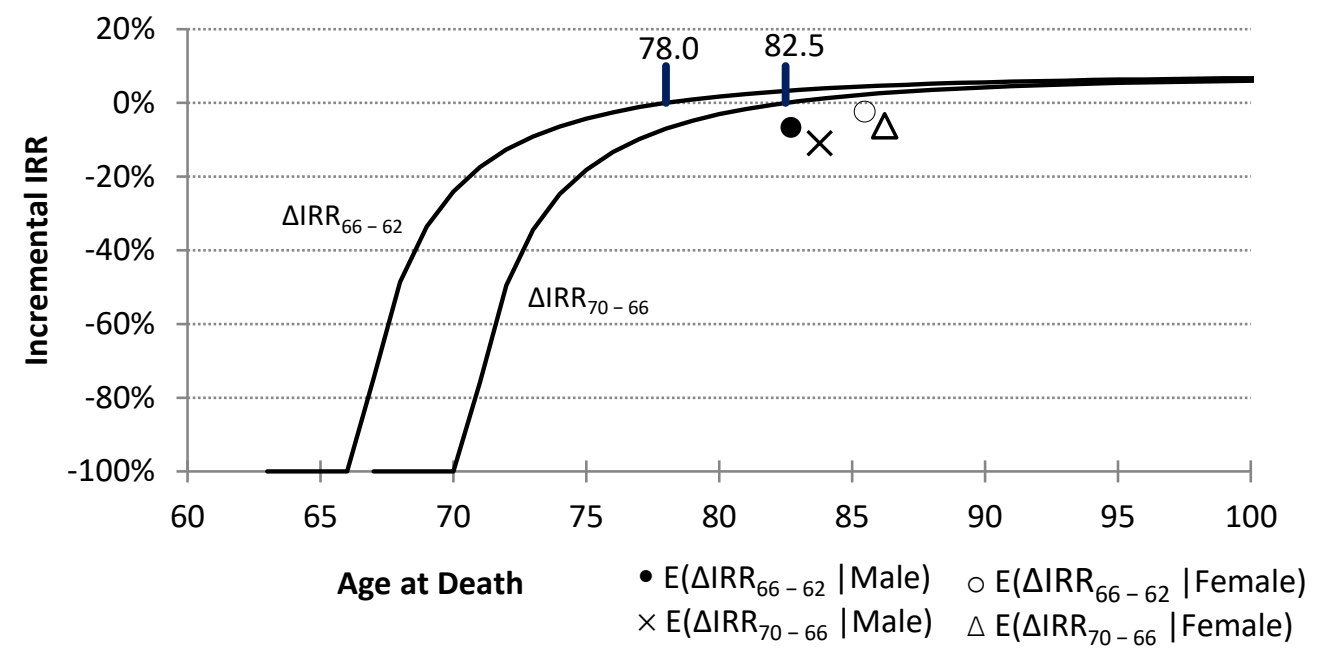

Figure 3. Incremental IRR vs. age at death.

Figure 3 also includes the expected IRR for both genders and both incremental choices plotted at the expected ages at death. Because these values do depend on the mortality distributions, it should be noted that the probabilities used for $\Delta \mathrm{IRR}_{70-66}$ are age at death given alive at 66 rather than the given alive at 62 used previously. Table 6 details the expected return and standard deviations for the incremental IRRs.

Table 6. Summary statistics for incremental IRR.

$$
\text { Total Female Male }
$$

\begin{tabular}{lrrrrrr} 
& $66-62$ & $70-66$ & $66-62$ & $70-66$ & $66-62$ & $70-66$ \\
\cline { 2 - 7 }$(\Delta \mathrm{IRR})$ & $-6.65 \%$ & $-11.00 \%$ & $-2.43 \%$ & $-6.22 \%$ & $-4.45 \%$ & $-8.48 \%$
\end{tabular}

$\begin{array}{lllllll}\text { Std. dev. } & 26.5 \% & 29.1 \% & 21.7 \% & 24.8 \% & 24.2 \% & 27.0 \%\end{array}$




\section{Impact of race, individual health, and heredity}

The prior analysis has focused on mortality risk for an "average" individual, male or female.

Decision-making by individuals can consider more specific indicators such as likely life span.

There are lifestyle choices (tobacco, drugs, exercise, etc.) and family histories that can shift the mortality expectation for an individual. These differences are difficult to characterize, but mortality distributions for demographic sub-populations can be used for insight into how incremental NPV and IRR results shift with the mortality distributions of individuals. There are groups with shifted mortality curves from the population at large. As shown in Figure 4, black males have a mortality curve that is shifted towards earlier death, and Hispanic females have a mortality curve that is shifted towards later death, all given that the person is alive at 62. Thus, they represent somewhat lower and higher life spans. The difference in their median age at death is 8.15 years. Use of this data was prompted by Docking, Fortin, and Michelson (2011), which also included the use of incremental IRRs.

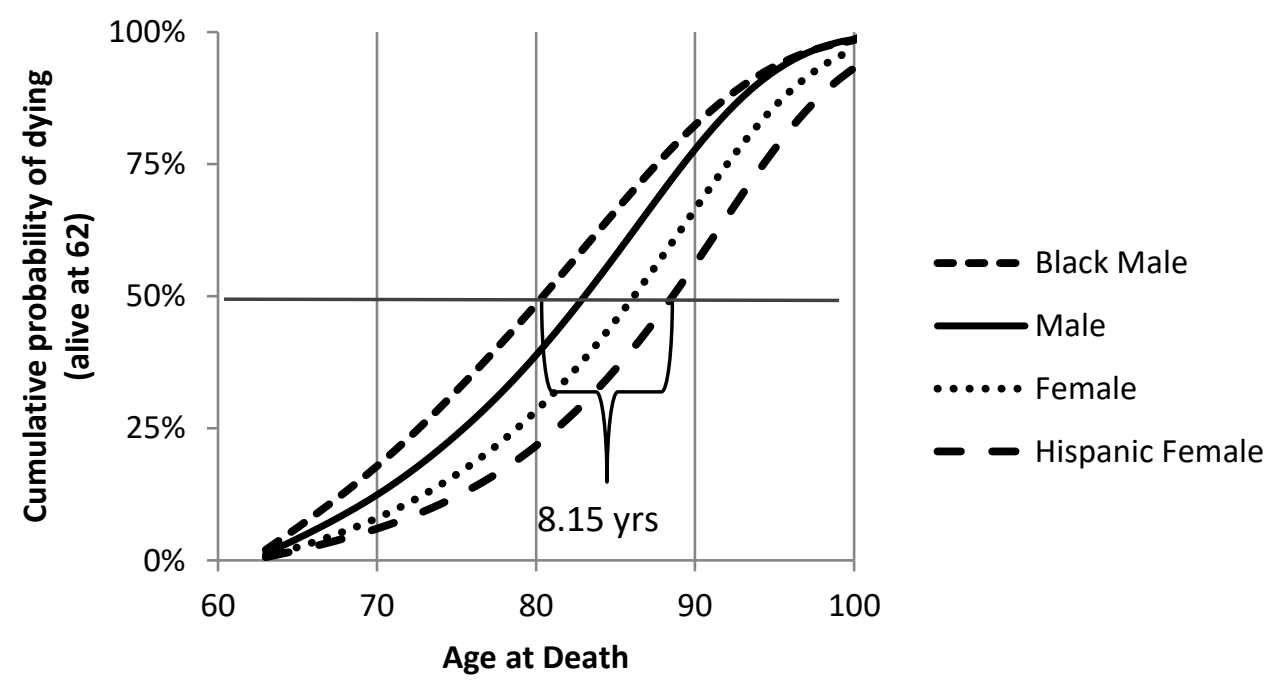

Figure 4. Mortality curves for four groups; assumes alive at 62. 
Table 7 summarizes the results for incremental NPV analyses for the total population and 4 sub-populations. Most of the expected incremental NPVs are negative. The four that are positive have large coefficients of variation ranging from 1.93 to 13.13 . The results for black males have more negative expected values than all males and slightly larger standard deviations. Only for Hispanic females does the $\mathrm{E}(\triangle \mathrm{NPV})$ exceed half of the standard deviation.

Table 7. NPV results for different mortality curves.

\begin{tabular}{lrrr|rrr} 
& \multicolumn{3}{c|}{ Delay from 62 to 66} & \multicolumn{3}{c}{ Delay from 66 to 70} \\
Group & $\mathrm{E}(\Delta \mathrm{NPV})$ & \multicolumn{1}{c|}{$\sigma$} & \multicolumn{1}{c|}{$\mathrm{CV}$} & $\mathrm{E}(\Delta \mathrm{NPV})$ & $\sigma$ & $\mathrm{CV}$ \\
\hline Black Male & $-\$ 8,947$ & $\$ 41,924$ & -4.85 & $-\$ 23,984$ & $\$ 43,095$ & -1.80 \\
Male & $-\$ 185$ & $\$ 40,078$ & -216.77 & $-\$ 17,431$ & $\$ 41,951$ & -2.41 \\
Total & $\$ 5,821$ & $\$ 40,004$ & 6.87 & $-\$ 11,512$ & $\$ 42,533$ & -3.69 \\
Female & $\$ 11,169$ & $\$ 38,994$ & 3.49 & $-\$ 6,299$ & $\$ 42,176$ & -6.70 \\
Hispanic Female & $\$ 19,696$ & $\$ 38,018$ & 1.93 & $\$ 3,179$ & $\$ 41,737$ & 13.13
\end{tabular}

Table 8 summarizes the incremental IRRs for the total population and 4 sub-populations. All of the expected incremental IRRs are negative, all of the standard deviations are large, and the coefficients of variation range from -2.06 to -51.68 . The smallest standard deviation is $19.3 \%$ (for Hispanic females, when delaying from 62 to 66 ). None of the delay strategies is attractive for any of the groups. Raising the median age at death to nearly 89 (Hispanic females) or lowering it to 80 (Black males) does not change the conclusion.

Table 8. Incremental IRRs for different mortality curves.

\begin{tabular}{lccc|ccc} 
& \multicolumn{2}{c|}{ Delay from 62 to 66} & \multicolumn{3}{c}{ Delay from 66 to 70} \\
Group & EV & $\sigma$ & CV & EV & $\sigma$ & CV \\
\hline Black Male & $-11.5 \%$ & $31.0 \%$ & -2.70 & $-16.1 \%$ & $33.1 \%$ & -2.06 \\
Male & $-6.6 \%$ & $26.5 \%$ & -3.99 & $-11.0 \%$ & $29.1 \%$ & -2.65 \\
Total & $-4.5 \%$ & $24.2 \%$ & -5.44 & $-8.5 \%$ & $27.0 \%$ & -3.19 \\
Female & $-2.4 \%$ & $21.7 \%$ & -8.92 & $-6.2 \%$ & $24.8 \%$ & -3.99 \\
Hispanic Female & $-0.4 \%$ & $19.3 \%$ & -51.68 & $-3.3 \%$ & $21.8 \%$ & -6.55
\end{tabular}


The conclusion that smaller differences in expected value are less important than larger differences in risk seems to be robust. In addition, when considering individual circumstances, health and longevity issues are more likely to be identified in the short-term than in a possible future that is 30 years or more away.

\section{Conclusions and Suggestions for Further Work}

Expected values and standard deviations have long been used together to evaluate investments, capital projects, and alternative engineering design choices—but not when to start collecting social security benefits. This work adds consideration of the standard deviations of $\triangle \mathrm{NPVs}$ and $\Delta$ IRRs for evaluating when to start collecting U.S. social security benefits for single individuals.

- As confirmed in this work, previous work has shown that expected NPV values for different starting ages are similar. Thus, $\triangle \mathrm{NPV}$ s for delay are small. In contrast, the standard deviations presented here are larger with coefficients of variation ranging from 1.93 to 13.31 for $\triangle \mathrm{NPVs}$ that are positive. If the $\triangle \mathrm{NPV}$ s are negative, then any level of risk indicates that delay is a dominated alternative when evaluated by these two criteria.

- $\Delta$ IRRs have been previously presented for delaying benefits, but without calculating standard deviations. By these measures starting early is clearly better. Expected $\Delta$ IRRs for 5 mortality distributions are all negative - ranging from $-3.3 \%$ to $-16.1 \%$. The standard deviations are large - ranging from $19.3 \%$ to $33.1 \%$.

- For ages before the full retirement age, the expected values and standard deviations do not imply that someone should retire in order to begin collecting. The income from working is very likely to exceed social security benefits. 
- Social security may be the only source of retirement income, or it may be part of an individual's retirement planning that includes an investment portfolio composed of assets, such as stocks, bonds, and Treasury bills. Historical and projected performance of such assets is most commonly measured by expected returns and the standard deviations of return. Knowing the $\Delta$ IRRs expected return and standard deviation for social security decisions is a starting point in considering social security as part of an investment portfolio.

- While differences in risk are greater than differences in expected return, these quantitative results must be considered in a broader framework. This work has described some of the most important behavioral and qualitative factors that may contribute to or dominate the choice of when to start benefits. Only individuals know their situation and their motivations.

- It is fundamentally important to recognize that retirement benefits, even when started early, address longevity risk. Delaying benefits gains incremental reductions in longevity risk while incrementally increasing mortality risk.

- Because this work is about decision-making by individuals, a key question is how much are the results influenced by mortality distributions shifted to earlier or later death. Such shifts are an important part of the behavioral and qualitative factors that must be considered. Some level of individual differences corresponds with differences in mortality distributions for gender and racial subgroups. At least at this level of difference, the results for expected values and standard deviation were consistent with results for females, males, and the total population. 
- The insight that standard deviations can be calculated using the same data used for expected total benefits and considered together with the expected values can be applied to other applications of mortality distributions. However, it is necessary to calculate $\triangle$ NPVs and $\triangle I R R s$ before a mortality distribution for age at death is applied to calculate expected values and standard deviations. Applying the mortality distribution to each starting choice independently is only of descriptive importance — not a valid way to calculate standard deviations of incremental choices.

Some of the following suggestions for further work are straightforward to execute while others are likely to be very challenging. To some extent, the suggestions are ordered by the expected level of difficulty. These are presented as examples—not as a comprehensive set.

- Consider single individuals under the retirement system of another country that allows individuals to choose when to start receiving benefits and where those benefits depend on when they start. The rules, available choices, the mortality distributions, the expected values, the standard deviations, etc. may all be different—but the methodology should be applicable.

- Consider choices for couples who are or were in a relationship where benefits such as the U.S. SSA's spousal and survivor's benefits are available. For example, in the U.S. after 9 months of marriage a new spouse can qualify for survivor's benefits and after 1 year for spousal benefits. After 10 years of marriage a divorced spouse can claim spousal or survivor's benefits if unmarried and 62. Because of the complexity of potential strategies and the myriad combinations of ages and SS 
earnings, it is suggested that special cases such as spouses with the same age be analyzed first.

- An assumption of independent mortality distributions is a likely starting point for analysis of choices for couples. However, there is evidence that the distributions are not independent. Most clearly, both partners may die with a common cause such as an auto accident. Even without a common cause there is some level of correlation. Nevertheless, computing incremental differences between choices before calculating expected values and standard deviations seems necessary.

- Portfolio theory is well developed for financial assets, but the right to receive benefits from social security is a completely different type of asset with a mortality distribution rather than market performance as the driver of uncertainty. Is there a way to integrate these or at least consider both when making choices in both? For example, being qualified for a higher social security benefit might imply that a higher level of financial risk would be acceptable. This is of particular interest because a common investment guideline is that exposure to more volatile assets such as stocks should shrink as age increases.

\section{Acknowledgement}

The authors would like to thank the editors and reviewers for the detailed comments and recommendations that were literally the best and most helpful we have ever received.

\section{Notes on contributors}

TED Eschenbach, PE, is the principal of TGE Consulting, an emeritus professor at the University of Alaska Anchorage, and EMJ's founding editor emeritus. He is a Fellow of ASEE, ASEM, and IISE. 
He has over 300 publications and presentations, including 20 editions of 4 engineering economy titles, 6 best paper awards at conferences, and the 2009 Grant award. In 2016 he received ASEE's biannual National Engineering Economy Teaching Excellence Award. He earned his B.S. from Purdue in 1971, his M.S. in operations research in 1973 and his Ph.D. in IE in 1975 from Stanford University, and his MCE from UAA in 1999.

NEAL A. LEWIS, CPEM, received his Ph.D. in engineering management in 2004 and B.S. in chemical engineering in 1974 from the University of Missouri-Rolla and his MBA in 2000 from the

University of New Haven. He has over 25 years of industrial experience at Procter \& Gamble and Bayer. He is teaching at Fairfield University and Oregon State University. Previously, he taught at UMR, Marshall University, the University of Bridgeport, and the University of New Haven. He has over 100 publications and presentations, including 2 books, 2 best paper awards at conferences, the 2009 Grant award (TEE), and the 2005 Eschenbach award (EMJ). Neal is a Fellow of ASEM.

\section{References}

Ahn, D-H., and Yoon, S.-Y. (2011) Endogenous labor/leisure/investment choice under time constraints. Journal of Financial and Quantitative Analysis, 46(4), 1157-1192.

Alleva, B.J. (2015) Minimizing the risk of opportunity loss in the social security claiming decision. The Journal of Retirement, 3(1), 67-86.

Arias, E. (2017) United States Life Tables, 2014. National Vital Statistics Reports, Volume 66, Number 4.

Bell, D.E. (1982) Regret in Decision Making under Uncertainty. Operations Research, 30(5), 961-981.

Blanchett, D. (2012) When to claim social security retirement benefits.” Journal of Personal Finance, 11(2), 36-87.

Boskin, M.J., Kotlikoff, L.J., Puffert, D.J., and Shoven, J.B. (1987) Social Security: A Financial Appraisal Across and Within Generations. National Tax Journal, 40(1), 19-34.

Cohn, D., and Taylor, P. (2010) Baby boomers approach 65 - glumly. Pew Research Center.

Coile, C., Diamond, P., Gruber, J. and Jousten, A. (2002) Delays in claiming social security benefits. Journal of Public Economics, 84, 357-385.

Cook, K.A., Jennings, W.W., and Reichenstein, W. (2002) When should you start your social security benefits? AAII Journal, 27-34.

DeWitt, L. (2010) The development of social security in America. Social Security Bulletin, $70(3), 1-26$. 
Davidoff, T., Brown, J.R., and Diamond, P.A. (2005) Annuities and individual welfare. The American Economic Review, 95, 1573-1590.

Docking, D.S., Fortin, R. and Michaelson, S. (2011) Influence of gender and race on the social security early retirement decision for single individuals. 2011 Conference of Academy of Business Education.

Eschenbach, T., Lewis, N., and Zhang, Y. (2012) When to Start Collecting Social Security: Designing a Case Study, in.Proceedings of the 2012 American Society for Engineering Education National Conference, San Antonio, Texas. Best paper for the Engineering Economy Division and for PIC I.

Friedman, J., and Phillips, H.E. (2010) The downside risk of postponing social security benefits. Financial Services Review, 19, 285-294.

Gradl, P.R., Youngblood, A.D., Componation, P.J., and Gholston, S.E. (2009) Considering risk within net present value: calculations for government projects. The Engineering Economist, 54(2), 152-174.

Gustman, A.L., and Steinmeier, T.L. (2005) The social security early entitlement age in a structural model of retirement and wealth, Journal of Public Economics, 89(2-3), 441-463.

Ho, S.S.M., and Pike, R.H. (1998) Organizational Characteristics Influencing the Use of Risk Analysis in Strategic Capital Investments. The Engineering Economist, 43(3), 247-268.

Jivan, N.A. (2004) How can the actuarial reduction for social security early retirement be right? Center for Retirement Research at Boston College, 11.

Kauder, E. (Sept 1953) Genesis of the marginal utility theory: from Aristotle to the end of the eighteenth century. The Economic Journal, (63)251, 638-650.

Knoll, M.A.Z. (2011) Behavioral and psychological aspects of the retirement decision." Social Security Bulletin, 71.

Kopczuk, W., and Lupton, J. P. (2007) To leave or not to leave: The distribution of bequest motives. Review of Economic Studies, 74, 207-235.

Kotlikoff, L.J. (1996) Privatization of social security: how it works and why it matters. Tax Policy and the Economy, 10, 1-32.

Lewis, N., and Eschenbach, T. (2013) Extending the Case Study of When to Collect Social Security: Economic Decision Making for Couples, in Proceedings of the 2013 American Society for Engineering Education National Conference, Atlanta, Georgia.

Lockwood, L.M. (2012) Bequest motives and the annuity puzzle. Review of Economic Dynamics, 15, 226-243.

Lohmann, J.R. and Baksh, S.N. (1993) The IRR, NPV and payback period and their relative performance in common capital budgeting decision procedures for dealing with risk. The Engineering Economist, 39(1), 17-47.

Manakyan, N., Ervin, D. and Claggett, E. T. (Spring 2014) Take the money: Should you draw social security retirement benefits early. Retirement Management Journal, 4(1), 45-53.

Meyer, W., and Reichenstein, W. (2010) Social security: When to start benefits and how to minimize longevity risk. Journal of Financial Planning, 23, 49-59.

Mitchell, O. S., J. M. Poterba, M. J. Warshawsky, and J. R. Brown. "New Evidence on the Money's Worth of Individual Annuities.” The American Economic Review, 89 (1999), 12991318.

Muldoon, D., and Kopcke, R. W. (2008) Are people claiming social security benefits later? Center for Retirement Research at Boston College, Issue Brief Number 8-7.

Munnell, A.H., and Soto, M. (2005) Why do women claim social security benefits so early? 
Center for Retirement Research at Boston College, Issue in Brief No. 35.

Reichenstein, W., and Meyer, W. (2017) Social Security Strategies: How to Optimize Retirement Benefits $3^{\text {rd }}$.

Sass, S.A., Sun, W. and Webb, A. (2007) Why do married men claim social security benefits so early? Ignorance or cadishness? Center for Retirement Research at Boston College, Working Paper 2007-17.

Sass, S.A., Sun, W. and Webb, A. (2008) When should married men claim social security benefits? Center for Retirement Research at Boston College, Number 8-4.

Shoven, J.B., and Slavov, S. N. (2012) The decision to delay social security benefits: theory and evidence. National Bureau of Economic Research, Working Paper 17866.

Social Security Administration, (2004) How the day of birth affects benefits. Program Operations Manual System TN26 (01-04) at http://policy.ssa.gov/poms.nsf/lnx/0300615015.

Social Security Administration, (2016) Social security programs throughout the world: Europe, 2016. Pub. \# 13-11801 or www.ssa.gov/policy/docs/progdesc/ssptw.

Social Security Administration, (2017a) Social security programs throughout the world: Asia and the Pacific, 2016. Pub. \# 13-11802 or www.ssa.gov/policy/docs/progdesc/ssptw.

Social Security Administration, (2017b) Social security programs throughout the world: Africa, 2017. Pub. \# 13-11804 or www.ssa.gov/policy/docs/progdesc/ssptw.

Social Security Administration, (2018a) Social security programs throughout the world: the Americas, 2017. Pub. \# 13-11802 or www.ssa.gov/policy/docs/progdesc/ssptw.

Social Security Administration. (2018b) Fact Sheet, 2018 Social Security Changes.

Sun, W., and Webb, A. (2009) How much do households really lose by claiming social security at age 62? Center for Retirement Research at Boston College, Working Paper 2009-11.

Sun, W., and Webb, A. (2011) Valuing the longevity insurance acquired by delayed claiming of social security. The Journal of Risk and Insurance, 78, 907-929.

Yaari, M. E. (1965) Uncertain lifetime, life insurance, and the theory of the consumer. The Review of Economic Studies, 32, 137-150. 